\title{
Electrochemical and Spectroelectrochemical Comparative Study of Macrocyclic Thermally Activated Delayed Fluorescent Compounds: Molecular Charge Stability vs OLED EQE RollOff
}

Nyga, Aleksandra; Izumi, Saika; Higginbotham, Heather F.; Stachelek, Patrycja; Pluczyk, Sandra; de Silva, Piotr; Minakata, Satoshi; Takeda, Youhei; Data, Przemyslaw

Published in:

Asian Journal of Organic Chemistry

Link to article, DOI:

10.1002/ajoc.202000475

Publication date:

2020

Document Version

Peer reviewed version

Link back to DTU Orbit

Citation (APA):

Nyga, A., Izumi, S., Higginbotham, H. F., Stachelek, P., Pluczyk, S., de Silva, P., Minakata, S., Takeda, Y., \& Data, P. (2020). Electrochemical and Spectroelectrochemical Comparative Study of Macrocyclic Thermally Activated Delayed Fluorescent Compounds: Molecular Charge Stability vs OLED EQE RollOff. Asian Journal of Organic Chemistry, 9(12), 2153-2161. https://doi.org/10.1002/ajoc.202000475

\section{General rights}

Copyright and moral rights for the publications made accessible in the public portal are retained by the authors and/or other copyright owners and it is a condition of accessing publications that users recognise and abide by the legal requirements associated with these rights.

- Users may download and print one copy of any publication from the public portal for the purpose of private study or research.

- You may not further distribute the material or use it for any profit-making activity or commercial gain

- You may freely distribute the URL identifying the publication in the public portal 


\section{ASIAN JOURNAL}

\section{OF ORGANIC CHEMISTRY}

www.asianjoc.org

\section{Accepted Article}

Title: Electrochemical and Spectroelectrochemical Comparative Study of Macrocyclic Thermally Activated Delayed Fluorescent Compounds: Molecular Charge Stability vs OLED EQE Roll-Off

Authors: Aleksandra Nyga, Saika Izumi, Heather F. Higginbotham, Patrycja Stachelek, Sandra Pluczyk, Piotr de Silva, Satoshi Minakata, Youhei Takeda, and Przemyslaw Data

This manuscript has been accepted after peer review and appears as an Accepted Article online prior to editing, proofing, and formal publication of the final Version of Record (VoR). This work is currently citable by using the Digital Object Identifier (DOI) given below. The VoR will be published online in Early View as soon as possible and may be different to this Accepted Article as a result of editing. Readers should obtain the VoR from the journal website shown below when it is published to ensure accuracy of information. The authors are responsible for the content of this Accepted Article.

To be cited as: Asian J. Org. Chem 10.1002/ajoc.202000475

Link to VoR: https://doi.org/10.1002/ajoc.202000475 


\title{
Electrochemical and Spectroelectrochemical Comparative Study of Macrocyclic Thermally Activated Delayed Fluorescent Compounds: Molecular Charge Stability vs OLED EQE Roll-Off
}

\author{
Aleksandra Nyga, ${ }^{\ddagger[a]}$ Saika Izumi, ${ }^{\ddagger[b]}$ Heather F. Higginbotham, ${ }^{[c]}$ Patrycja Stachelek, ${ }^{[d]}$ Sandra \\ Pluczyk, ${ }^{[a]}$ Piotr de Silva, ${ }^{*[e]}$ Satoshi Minakata, ${ }^{*[b]}$ Youhei Takeda*[b] and Przemyslaw Data ${ }^{*[a, f]}$
}

[a] A. Nyga, Dr. S. Pluczyk, Prof. Dr. P. Data

Faculty of Chemistry

Silesian University of Technology

M. Strzody 9, 44-100 Gliwice (Poland)

E-mail: przemyslaw.data@polsı.pl

[b] S. Izumi, Prof. Dr. S. Minakata, Prof. Dr. Y. Takeda

Department of Applied Chemistry

Graduate School of Engineering

Osaka University

Yamadaoka 2-1, Suita, Osaka 5650871 (Japan)

E-mail:minakata@chem.eng.osaka-u.ac.jp; takeda@chem.eng.osaka-u.ac.jp

[c] Dr. H. F. Higginbotham

School of Science

Swinburne University of Technology

Hawthorne, Victoria (Australia)

[d] Dr. P. Stachelek

Physics Department

Durham University

South Road, Durham DH1 3LE (United Kingdom)

[e] Prof. Dr. P. de Silva

Department of Energy Conversion and Storage

Technical University of Denmark

Anker Engelunds Vej 301, 2800 Kgs. Lyngby (Denmark)

E-mail: pdes@dtu.dk

[f] Prof. Dr. P. Data

Centre of Polymer and Carbon Materials

Polish Academy of Science

M. Curie-Sklodowskiej 34, 41-819, Zabrze (Poland)

¥ These authors contributed equally. Supporting information for this article is given via a link at the end of the document.

\begin{abstract}
In this work, we present how a small change in molecular structure can affect the electrochemical stability of organic compounds. A new electron donor-acceptor-donor-acceptor (D-A$\mathrm{D}-\mathrm{A})$ macrocyclic $\pi$-conjugated compound (tBuMC) comprising of dibenzophenazine as As and $N, N$-bis(t-butylphenyl)- $p$ phenylenediamines as Ds has been synthesized. The photophysical investigation uncovered that $\boldsymbol{t}$ BuMC showed thermally activated delayed fluorescence and that the organic light-emitting diodes (OLEDs) fabricated with $\mathbf{t B u M C}$ as the emitter achieved high external quantum efficiency (EQEs) of ca. 10\%. However, the OLED with tBuMC showed a slightly lower EQE than that of the OLED with MC $(11.6 \%)$ and showed greater EQE roll-off. Comparative studies on electrochemical properties of $\mathbf{t B u M C}, \mathbf{M C}$, and a linear analogue (Linear) revealed the introduction of $t$-Bu groups in the D-A-D-A scaffold causes a significant change in redox behavior. Full electrochemical and spectroelectrochemical studies gave clues to understand how the steric hindering group is affecting the charge distribution in the new molecules which results in a significant difference in the OLED roll-off. The electrochemical investigations together with UV-Vis-NIR and EPR analyses supported by quantum chemical theoretical calculations were performed, which provided us insights on the effect of structural modification on the redox properties of the D-A-D-A scaffold.
\end{abstract}

\section{Introduction}

The development of novel organic emitters is one of the main key branches of the science of organic electronics over the years. The first promising materials showing luminescent properties include complexes of noble metals with organic ligands, which are characterized by highly efficient phosphorescence. The introduction of heavy transition metals to organic fragments allows for the achievement of previously unattainable performances above $5 \%$ external quantum efficiency (EQE). ${ }^{[1]}$ One of the most known examples of this kind emitters is tris(2phenylpyridine)iridium(III), which has been widely studied by many researchers. ${ }^{[2-5]}$ On the other hand, the use of noble metals such as iridium(III) and platinum(II) for those emitters significantly increases the production costs, and even more importantly, causes waste disposal problem. This fact speeds up the development of new generations of metal-free organic emitters. ${ }^{[6]}$

One of the most promising phenomena in the field of metalfree organic light-emitting diodes (OLEDs) is thermally activated delayed fluorescence (TADF). The fundamental phenomenon that allows for significant enhancement of electroluminescence performance of TADF emitters is the reverse intersystem crossing (rISC). The rISC is a specific endothermic and spin-forbidden process, which transfers the excited triplet state into the excited 
singlet state $\left(T_{1} \rightarrow S_{1}\right)$. The possibility of occurrence of rISC depends on the energy difference between the two states ( $T_{1}$ and $\mathrm{S}_{1}$ ), which is known as the singlet-triplet energy gap $\left(\Delta E_{\mathrm{ST}}\right)$. To overcome the activation energy for rISC, the $\Delta E_{\mathrm{ST}}$ has to be a very small (ca. $<0.3 \mathrm{eV}$ ), and the motions and vibrations of atoms in a molecule also give a huge impact on the rISC efficiency and thereby TADF phenomena. ${ }^{[7-14]}$ Another key factor for TADF emitter is their specific molecular structures: many of the investigated TADF molecules have a highly twisted $\pi$-conjugated donor-acceptor (D-A) architecture. Their ability to transport hole and electron is a big advantage in designing emitters for the electricity-driven optoelectronic applications. ${ }^{[13]}$ Another benefit of such twisted D-A structures include the ability to manipulate the excited states and thereby regulate their properties by fluctuating conformations. Therefore, an increasing number of new, optimized, and even multifunctional TADF molecules based on the D-A scaffolds have been developed. ${ }^{[16-18]}$ Also, the development of value-added and multifunctional TADF molecules has tremendous meaning in materials sciences, as they can be used not only in display applications but also in sensing and optical imaging arena. ${ }^{[19]}$ More and more D-A systems comprising of structurally-diverse and large fragments have been reported, but they are still limited to linear and grafted structures.

From the viewpoint of chemical space of D-A type TADF emitters, an extremely poorly explored and underestimated class should be the macrocyclic m-conjugated TADF molecules. The first macrocyclic TADF material in literature, that is Sn-porphyrin complex, was reported in 2009 by the Adachi group. ${ }^{[20]}$ Nonetheless, they contain heavy and toxic metals, and the delayed emissions from the materials in OLED devices are faint. A few years later, Kanbara et al. reported the TADF behaviour of azacalix $[n](2,6)$ pyridines, which represents the first metal-free purely organic macrocyclic TADF compound. ${ }^{[21]}$ However, the TADF efficiency is very low due to the large $\Delta E_{S T}$ values $(>600$ $\mathrm{meV}$ ). Recently, we have developed a D-A-D-A-type $\pi$ conjugated macrocycle which displays an efficient TADF, and the OLED device fabricated with the emitter achieved a high EQE $(11.6 \%)^{[22]}$ Notably, the macrocyclic TADF molecule induces much higher TADF contribution than a linear analogue, showcasing the validity of macrocyclic design for TADF emitter.

Nevertheless, from the viewpoint of device engineering, developing an emitter with a high PLQY and low $\Delta E_{S T}$ is not enough to have efficient OLED. One of the frequent issues in OLED devices is the roll-off of the working device, and usually, it is possible to overcome the roll-off issue by device optimization. This is true if the problem lies in the device structure. But, what we would like to point out here is that sometimes the problem lies in the molecular structure. Due to this, the investigation of an electrochemical and photophysical preliminary analysis of potential emitters, which is the first step in the electroactive compound analysis, is fundamentally important for device optimization. Voltammetry techniques allow us to determine the values for ionization potential (IP), electron affinity (EA), and energy gap, which with a combination of molecular modeling calculations let scientists select the initial promising emitters. In addition, the use of coupled techniques, which can be conducted in a combination of spectroscopic and electrochemical techniques, enables us to understand the changes occurring in the studied molecules under varying voltage conditions. All of this allows for the characterization of individual compounds as well as understanding their subsequent behavior that occurs in OLED devices.

Herein, we would like to show how a small change in molecular structure affects the properties of D-A-D-A macrocyclic emitters ( $\mathbf{M C}^{[22]}$ and $\boldsymbol{t B u M C}$, Figure 1). The electrochemical and spectroelectrochemical analysis using techniques such as cyclic voltammetry, electron paramagnetic resonance spectroscopy, and UV-Vis-NIR spectroelectrochemistry explain the steric hindrance effect of the macrocyclic compounds and the linear analogue (Linear, Figure 1). By these measurements, we can explain the lack of stability of TADF-based OLED device with $t$ BuMC.
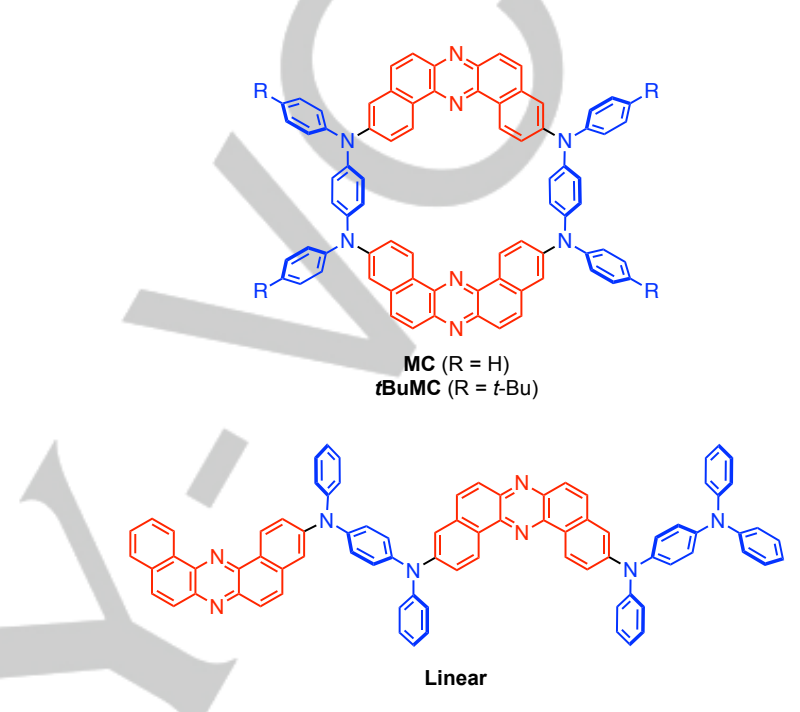

Figure 1. Compounds studied in this work.

\section{Results and Discussion}

\section{Materials Synthesis}

Macrocycle MC and its linear analogue Linear were synthesized according to the synthetic procedures reported in our previous paper. ${ }^{[22]}$ To investigate the effect of a slight modification of the molecular structure of MC, we designed a new macrocycle tBuMC that has four $t$-butyl groups at the para-position of the exterior aromatic rings (Figure 1). The synthesis of $t$ BuMC was successfully completed similarly to that for MC (for the detailed procedures, see the $\mathrm{SI}$ ).

\section{Electrochemical Study}

A general approach for analysis of organic conjugated compounds for electronic applications is to investigate the behaviour of molecules under electrical stress. In this matter, the cyclic voltammetry (CV) is a quite useful technique. The CV gives an insight into what processes are involved in the doping process and during the formation of charge carriers like polarons and bipolarons. Also, CV allows for estimation of the IP and EA of the compounds.

Therefore, firstly, we analyzed macrocyclic (MC, tBuMC) and linear (Linear) D-A-D-A compounds by CV (Figure 2). MC and Linear were previously studied only with CV for OLED application to determine the IP and EA, ${ }^{[22]}$ but more detailed electrochemical analyses and comparison of their redox 
processes remained to be explored. As described in the previous our paper, ${ }^{[22]} \mathbf{M C}$ and Linear in $\mathrm{CH}_{2} \mathrm{Cl}_{2}$ (c $10^{-4} \mathrm{M}$ order) show 2step reversible oxidation and a 1 -step reversible reduction in cyclic voltammogram (Figure $2 \mathrm{a}$ and $\mathrm{c}$ ). Different from these compounds, the newly synthesized compound $\boldsymbol{t B u M C}$ displayed 2-step oxidation where the first redox couple $\left({ }^{\mathrm{ox}} E_{1 / 2}=+0.23 \mathrm{~V}\right)$ is reversible but the second one $\left({ }^{0 \times 2} E_{1 / 2}=+0.63 \mathrm{~V}\right)$ is quasireversible with an untypically high peak current (Figure 2b). Also, it is noted that the peak current of the 2 nd oxidation process decreased as the redox cycle repeats. Although the second oxidation process of $t B u M C$ is quasi-reversible, any additional peaks related to the formation of byproducts through the redox process was not observed (Figure $2 \mathrm{~b}$ ). In addition, the other part of the CV was not affected by the repetition. Such behavior suggests that the decrease in the current peak is not connected with the deposition of low conducting material on the electrode or with the chemical degradation of $t$ BuMC. As for the reduction process, a single reversible redox couple at $-1.89 \mathrm{~V}$ was observed (Figure $2 \mathrm{~b}$ ), which behavior is in good agreement with MC.
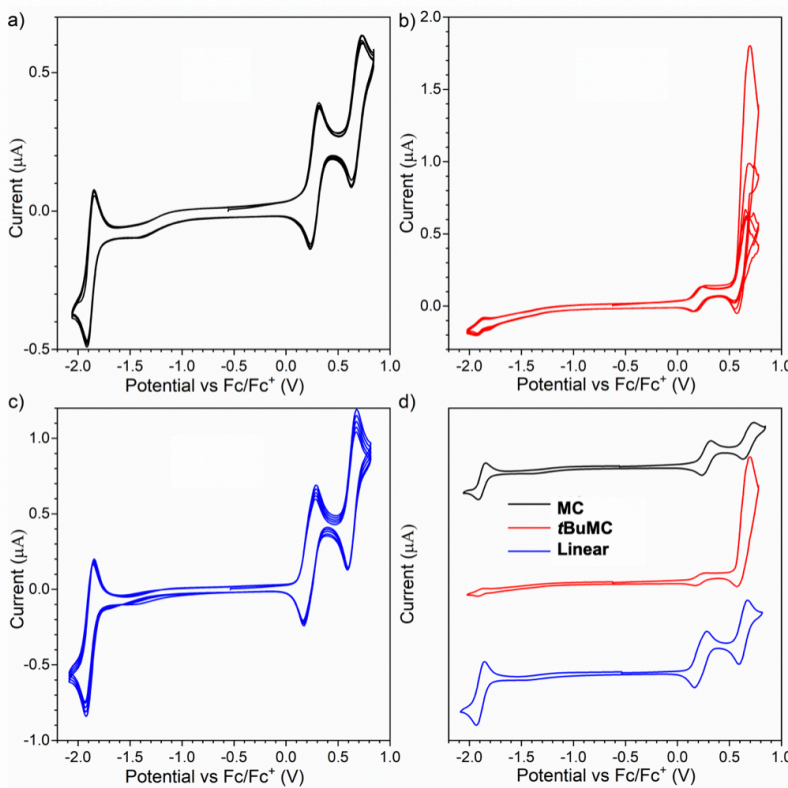

Figure 2. Cyclic voltammograms of (a) $\mathbf{M C}(0.50 \mathrm{mM})$, (b) $\mathbf{t B u M C}(0.25$ $\mathrm{mM})$, and (c) Linear $(0.50 \mathrm{mM})$ in $\mathrm{CH}_{2} \mathrm{Cl}_{2}$ containing $0.1 \mathrm{M} \mathrm{Bu}_{4} \mathrm{NBF}_{4}$. Electrodes: working $(\mathrm{Pt})$, counter $(\mathrm{Pt}$ wire), and reference $(\mathrm{Ag} / \mathrm{AgCl})$. Scan rate: $50 \mathrm{mV} \mathrm{s}^{-1}$. (d) Comparison of the cyclic voltammograms of $\mathbf{M C}$, tBuMC, and Linear.

In general, all compounds have similar first oxidation $\left({ }^{\circ \mathrm{ox}} E_{1 / 2}{ }^{\mathrm{cV}}\right.$ ) and reduction ( ${ }^{\text {red }} E_{1 / 2}{ }^{\mathrm{cV}}$ ) potentials and therefore similar IP/EA energies (Table 1). Importantly, the IPs and EAs are close to those of the donor (i.e., $N, N, N^{\prime}, N^{\prime}$-tetraphenylenediamine) $)^{[23]}$ and the acceptor unit (i.e., DBPHZ) ${ }^{[24]}$ respectively. This indicates the localization of the HOMOs and LUMOs on the D and A units, respectively, due to effective decoupling between the Ds and As, which are beneficial for small $\Delta E_{\mathrm{ST}}$. But, when one carefully compares the first oxidation potentials of $M C$ and $t B u M C$, one will notice that the ${ }^{{ }^{\circ} 1} E_{1 / 2}{ }^{\mathrm{CV}}$ of $t$ BuMC is more negative $(0.23 \mathrm{~V})$ than that of MC $(0.27 \mathrm{~V})$ by $0.04 \mathrm{~V}$ (Table 1$)$. This negative shift would be caused by the introduction of four $\sigma$-donating alkyl $(t-\mathrm{Bu})$ groups at the $p$-position of the external aromatic rings on the donors. Also, the introduction of $t$-Bu groups significantly affects the second oxidation process as already mentioned above.
The absolute values and relative shifts in the first oxidation potentials are in good qualitative agreement with the IPs calculated using density functional theory (DFT) (calc/P for MC:5.10 eV, calcIP for tBuMC: $5.02 \mathrm{eV}$, for the details of calculations and more results, see Table $\mathrm{S} 1$ in the $\mathrm{SI}$ ). The calculations reveal also that the removal of the second electron to form a diradical dication would occur at the same potential, which clarifies the 2-electron character of the first oxidation wave in the $\mathrm{CV}$. Note that the kinetic factors may still lead to a mixture of mono- and dications. The second oxidation wave is predicted to correspond to further oxidation to monoradical trication and closed-shell tetracation, which are more thermodynamically stable than triradical and tetraradical species.

\begin{tabular}{|c|c|c|c|c|c|}
\hline Compd & $\begin{array}{l}{ }^{\circ \times 1} E_{1 / 2} \mathrm{CV} \\
{[V]^{[a]}}\end{array}$ & $\begin{array}{l}{ }^{0 \times 2} E_{1 / 2} \mathrm{cV} \\
{\left[V^{[b]}\right]^{[b]}}\end{array}$ & $\begin{array}{l}{ }^{\mathrm{red}} E_{1 / 2} \mathrm{cV} \\
{[\mathrm{V}]^{[c]}}\end{array}$ & $\mathbb{I P}[\mathrm{eV}]^{[\mathrm{d}]}$ & $\begin{array}{l}E A \\
{[e V]^{[d]}}\end{array}$ \\
\hline MC & $0.27^{[\mathrm{e}]}$ & 0.68 & $-1.88^{[e]}$ & $5.37^{[\mathrm{e}]}$ & $3.22^{[\mathrm{e}]}$ \\
\hline tBuMC & 0.23 & 0.63 & -1.89 & 5.33 & 3.21 \\
\hline Linear & $0.22^{[e]}$ & 0.63 & $-1.89^{[e]}$ & $5.32^{[\mathrm{e}]}$ & $3.21^{\mathrm{ee}}$ \\
\hline
\end{tabular}

[a] ${ }^{\mathrm{ox} 1} E_{1 / 2} \mathrm{Cv}$ : average 1st oxidation potential measured with $\mathrm{CV}$; [b] ${ }^{\mathrm{o} \times 2} E_{1 / 2}{ }^{\mathrm{CV}}$ : average 2nd oxidation potential measured with $\mathrm{CV}$; [c] ${ }^{\mathrm{red}} E_{1 / 2}{ }^{\mathrm{CV}}$ : average reduction potential measured with $\mathrm{CV}$; [d] IP: ionization potential; EA: electron affinity; IP = ${ }^{\mathrm{ox} 1} E_{1 / 2}{ }^{\mathrm{CV}} / \mathrm{V}+5.1[\mathrm{eV}] ; \mathrm{EA}={ }^{\mathrm{red}} E_{1 / 2}{ }^{\mathrm{CV}} / \mathrm{V}+5.1[\mathrm{eV}] .{ }^{[25,26]}$; [e] The values are taken from ref. 22.

\section{Photophysics \& OLED devices}

Time-resolved luminescence spectroscopy of the compounds was performed in both non-polar Zeonex ${ }^{\circledR}$ host and CBP host, the latter of which was used to mimic the chemical environment within an OLED device. Within both hosts, each material shows emission within two distinct time regions. The first component of $t$ BuMC, which decays with a lifetime within the nanosecond time regime, is attributed to prompt emission from the singlet excited state, due to its temperature independence (Figure $3 a$ and $b$ ). The behaviour of $t B u M C$ is similar to those of MC and Linear. ${ }^{[22]}$ The emission spectra of $t$ BuMC acquired at nanosecond time delays in both of Zeonex ${ }^{\circledR}$ and CBP hosts show Gaussian shapes ascribed to the irradiation from the chargetransfer singlet excited state $\left({ }^{1} \mathrm{CT}\right)$, while in the millisecond regime, delayed emission is observed (Figure $3 \mathrm{c}$ and $\mathrm{d}$ ). Both delayed emissions (DEs) from the singlet and triplet states are observed within similar millisecond timescales, but these DEs are easily elucidated by spectral inspection at different temperatures. The $\mathrm{DE}$ of $t \mathrm{BuMC}$ observed in the millisecond region at room temperature $(300 \mathrm{~K})$ is well overlapped with the prompt CT emission spectra (Figure $3 a$ and $b$ ). According to the previous our work on MC, ${ }^{[22]}$ this DE is assignable to TADF. In contrast, emission from the triplet state is observed at a low temperature $(50 \mathrm{~K})$, with the onset triplet energy being at $2.34 \mathrm{eV}$ in Zeonex ${ }^{\circledR}$ and $2.14 \mathrm{eV}$ in CBP host (Figure $3 a$ and $b$ ). What is interesting is that the host significantly affects the triplet emission profiles: by changing the host from Zeonex ${ }^{\circledR}$ to CBP, the phosphorescence emission energy lowers by $0.20 \mathrm{eV}$, and the shape of emission spectrum turns from vibronic structured one $\left({ }^{3} \mathrm{LE}\right)$ to a shapeless Gaussian-like one $\left({ }^{3} \mathrm{CT}\right)$. The host affects not only the triplet state 
energy but also the ${ }^{1} \mathrm{CT}$ energy, and both ${ }^{1} \mathrm{CT}$ and ${ }^{3} \mathrm{CT}$ are lower in CBP than in Zeonex ${ }^{\circledR}$. As a consequence, the smallest $\Delta E_{\mathrm{ST}}$ gap $(0.15 \mathrm{eV}$ ) among all the investigated compounds (MC 0.18 $\mathrm{eV}$; Linear $0.20 \mathrm{eV})^{[22]}$ was achieved with tBuMC. Moreover, assuming that the rISC should be fed from the ${ }^{3} \mathrm{LE}\left(\mathrm{T}_{n}\right)$ to ${ }^{1} \mathrm{CT}\left(\mathrm{S}_{1}\right)$ that is allowed by the El-Sayed rule, ${ }^{[27]}$ the actual gap to be overcome for rISC would be lower, suggesting the faster rISC and higher TADF contribution in the emission than expected from the extracted $\Delta E_{S T}$ value.
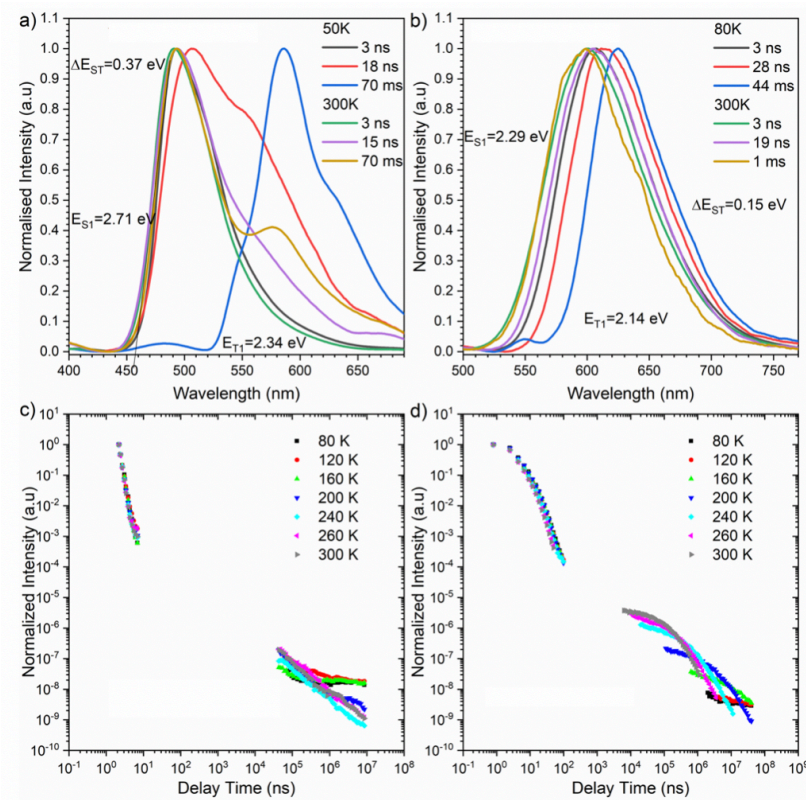

Figure 3. Normalized emission spectra of $\mathbf{t B u M C}$ in host matrices (a) Zeonex ${ }^{\circledR}(1 \mathrm{wt} \%)$ and (b) CBP $(10 \mathrm{wt} \%)$ at varying delay times at $300 \mathrm{~K}$ and $50 \mathrm{~K}$ or $80 \mathrm{~K}$; Emission intensities of $\boldsymbol{t B u M C}$ in host matrices (c) Zeonex ${ }^{\circledR}$ (1 wt $\%)$ and (d) CBP (10 wt\%) against delay time measured at a different temperature.

The investigated compounds were utilized as the TADF emitter in OLED devices (Figure 4). The device structure fabricated with MC and Linear compounds was ITO/NPB (40 $\mathrm{nm}) / 10 \% \mathrm{MC}$ or Linear in CBP $(30 \mathrm{~nm}) / \mathrm{TPBi}(50 \mathrm{~nm}) / \mathrm{LiF}(1$ $\mathrm{nm}) / \mathrm{Al}(100 \mathrm{~nm}) .{ }^{[22]}$ As for the device fabricated with $\mathbf{t B u M C}$, after long device optimization, the best structure was found to be ITO/HAT-CN (10 nm)/NPB (30 nm)/TAPC $(10 \mathrm{~nm}) / 7 \%$ tBuMC in CBP $(25 \mathrm{~nm}) / \mathrm{TPBi}(50 \mathrm{~nm}) / \mathrm{LiF}(1 \mathrm{~nm}) / \mathrm{Al}(100 \mathrm{~nm})$. Similar to $M C$, the OLED fabricated with $t B u M C$ presents a much higher external quantum efficiency (EQE ca. 10.4\%) than that with Linear (6.9\%), which also much higher than OLEDs with the 1st generation fluorescence emitter (ca. $5 \%$ ). However, the EQE of the tBuMCbased device was lower than that with MC (11.6\%), ${ }^{[22]}$ and it showed substantial roll-of (Figure $4 b$ ).

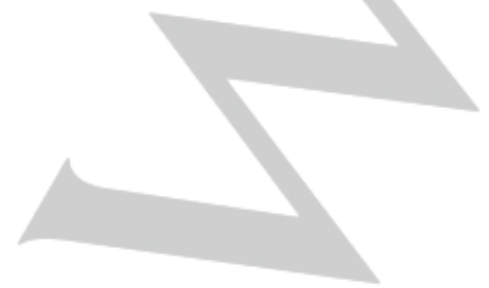

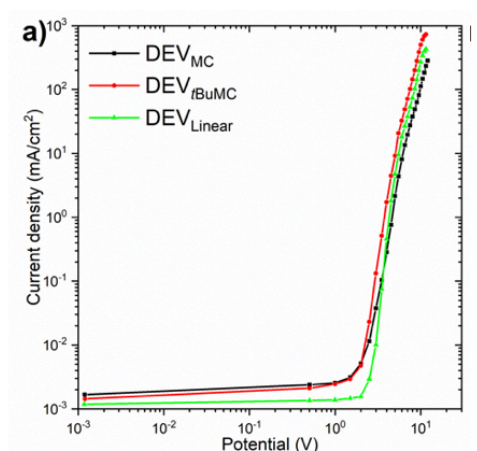
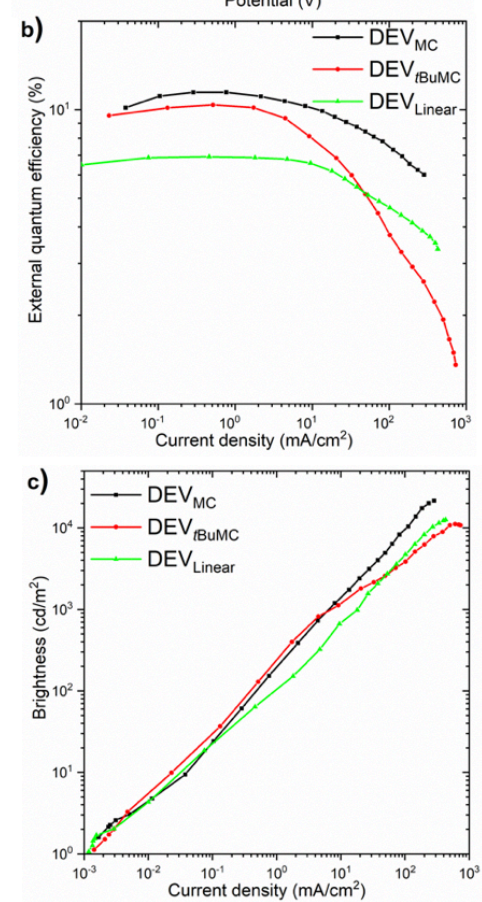

The luminance of device based on $\mathbf{t B u M C}$ is quite high (more than $11,000 \mathrm{~cd} / \mathrm{m}^{2}$ ) but still lower than those for both devices fabricated with Linear (ca. $12,500 \mathrm{~cd} / \mathrm{m}^{2}$ ) and MC (> $23,000 \mathrm{~cd} / \mathrm{m}^{2}$ ) emitters. In the lower voltage, the $t$ BuMC-based device exhibits a higher brightness than others, but after $5 \mathrm{~V}$ (ca. $8 \mathrm{~mA} / \mathrm{cm}^{2}$ ) the process connected to the roll-off is being observed, the emission increases with a lower rate. Device optimization which usually helps to decrease the roll-off did not help in the case of $t$ BuMC emitter. Even after changing the host and increasing or decreasing the thickness of supporting layers, substantial lowering in the efficiency was observed. This suggests that the roll-off was caused not by the problems related to charge injection and/or device structure but by the one lying in emitter itself. It would be important to reveal how slight molecular modification affects its physicochemical properties from the viewpoint of materials design. For this purpose, we start a careful analysis of the compound under electrical stress.

\section{Potentiostatic UV-Vis-NIR spectroelectrochemistry}

Spectroelectrochemical analysis of the compounds reveals that electrochemical oxidation of neutral species gradually yields new vibronic bands between $500-800 \mathrm{~nm}$ (denoted as B1) and 800$1100 \mathrm{~nm}$ (denoted as B2) (Figure 5). At a glance, all cases look similar, but there are significant differences between them. After applying potential to neutral MC up to $0.50 \mathrm{~V}$, surprisingly, a 
significant rise of the bands connected to the neutral species $(250-550 \mathrm{~nm}$, Figure $5 \mathrm{a})$ and small rise of the B1. Subsequently, the rise of B2 was observed (Figure $5 \mathrm{a}$ ). This band corresponds to an intervalence charge-transfer (IV-CT) absorption band, which are commonly observed for radical cation species of class II/III $N, N, N$, $N$ '-tetraaryl-p-phenylenediamine derivatives. ${ }^{[28-30]}$ According to the theoretical calculations conducted, the IP of MC $(5.10 \mathrm{eV})$ and IP of its radical cation $(5.03 \mathrm{eV})$ are almost the same (for the details, see Table $\mathrm{S} 1$ in the $\mathrm{SI}$ ). This suggests two electrons are removed from $\mathbf{M C}$ at almost the same voltage. In conjunction with the fact that IV-CT bands were not shifted through the 1st oxidation, one electron was removed from each donor (two electrons in total) to form open-shelled semi-quinone diradical dication species through the 1st oxidation step. This concomitant two-electron oxidation is commonly reported with macrocyclic oligoarylamines. ${ }^{[31]}$ Above the voltage $0.50 \mathrm{~V}$, a quite fast increase of another IV-CT band (B1) and decrease of IV-CT band (B2) were observed, which should correspond to the second oxidation stage of the MC (Figure 5a). According to literature, the second one-electron-oxidation of $N, N, N^{\prime}, N^{\prime}$-tetraphenyl- $p$ phenylenediamine (TPPD) radical cation results in the rise of absorption at around $598 \mathrm{~nm}$, indicating the generation of openshelled diradical dication. ${ }^{[32]}$ Given the similar behaviour of MC, the second oxidation step would involve concomitant two-electron removal from the diradical dication species to generate monoradical trication and closed-shell tetracation species.
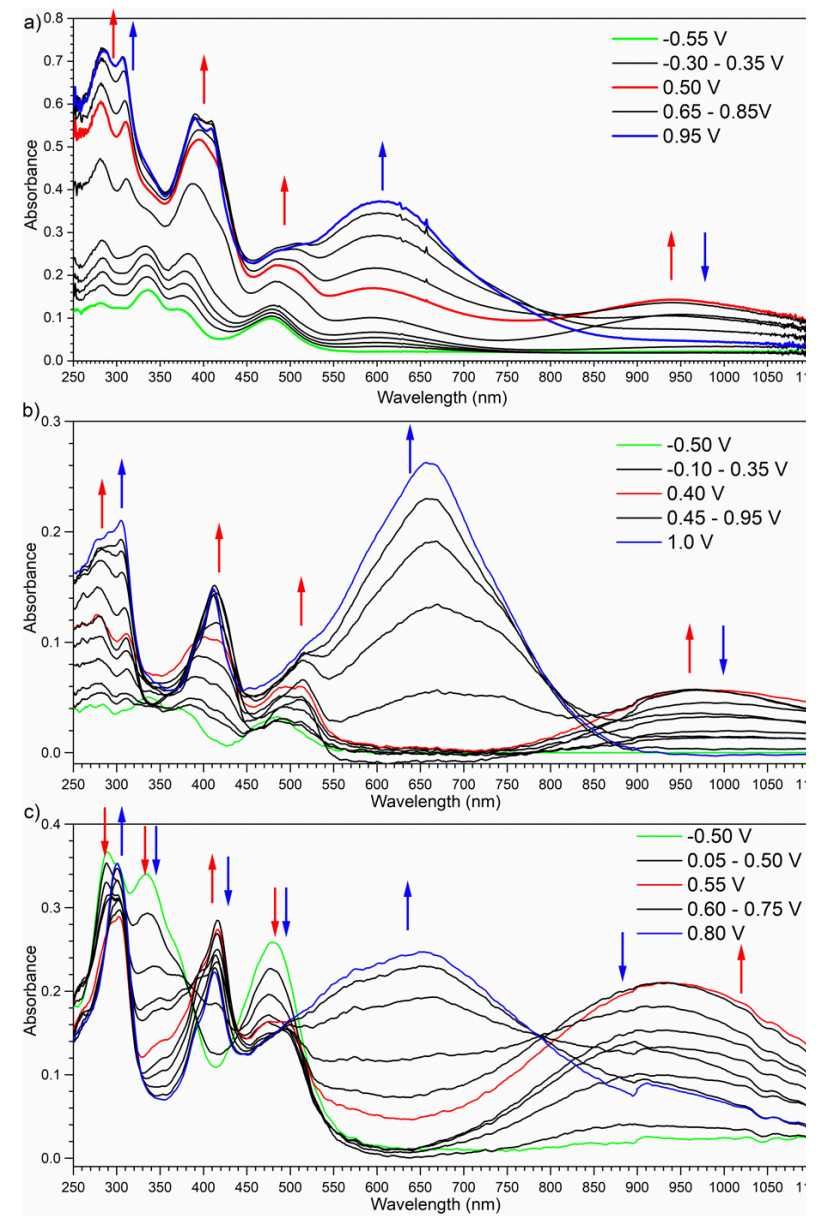

Figure 5. Potentiostatic UV-Vis-NIR spectroelectrochemistry of (a) 0.50 $\mathrm{mM} \mathrm{MC}$, (b) $0.25 \mathrm{mM}$ tBuMC, and (c) $0.50 \mathrm{mM}$ Linear in $\mathrm{DCM} \mathrm{Bu}_{4} \mathrm{NBF}_{4}$ $(0.1 \mathrm{M})$ electrolyte.
The spectroelectrochemical behavior of Linear looks more similar to that of TPPD and its derivatives: a couple of absorption bands ascribed to the neutral form of Linear gradually decreased, and the IV-CT bands (B2) and (B1) arise sequentially, showing isosbestic points (Figure $5 \mathrm{c}$ ). This behavior suggests the oxidation of Linear proceeds in a sequential manner. In contrast, the behavior of $\mathbf{t B u M C}$ looks like the mixture of processes observed in $\mathbf{M C}$ and Linear (Figure $5 \mathrm{~b}$ ). During the oxidation, a rise of new bands in the range of neutral form was observed, and then up to $0.40 \mathrm{~V}$, the rise of IV-CT band (B2) was observed. After crossing the first oxidation potential, a significant increase of B1 together with the decrease of B2 band was observed. From the analysis of simulated spectra (Figure S1-S3) the first conclusion which could be taken is that there is no new band forming between $250 \mathrm{~nm}$ and $450 \mathrm{~nm}$ so the rise of the neutral part is probably due to the diffusion of neutral species and increase the concentration in the double layer between the solution and electrode. As for the difference between the MC and $t B u M C$ in the first step, the absence of new band between $600-700 \mathrm{~nm}$ is proven by theoretical calculation (Figures S1 and S2), where MC cation absorption lay between $550-750 \mathrm{~nm}$ and tBuMC is hipsochromically shifted and lay between 450-600 nm (Figure S2).

The spectra calculated with time-dependent DFT corroborate this analysis (see SI for calculated spectra). The B2 band corresponds to the presence of monocationic species. While the calculated band for MC and $\mathbf{t B u M C}$ is red-shifted to 1100$1200 \mathrm{~nm}$, the agreement is much closer for Linear. Considering that the hole is localized on one donor unit in Linear and delocalized over both donors in the macrocycles, this could suggest that vibronic effects, which are not considered in the simulated spectrum, could lead to charge localization and blueshift of the band. The B1 band corresponds to the presence of trications and tetracations and is predicted to lie between the B2 and neutral bands, in agreement with the experiment.

\section{Potentiostatic EPR spectroelectrochemistry}

To gain information on the species formed in the electrochemical reactions, EPR spectroelectrochemical measurements were carried out. In the case of MC, the application of the potential of $0.3 \mathrm{~V}$ (vs. the $\mathrm{Fc} / \mathrm{Fc}^{+}$redox couple) led to the formation of species having unpaired spins, with the $g$-factor being 2.00301 (Figure 6a). As mentioned earlier, at this potential (the 1st oxidation process), concomitant two-electron removal occurs to generate diradical dication species $\mathbf{M C}^{2+}$. If the diradical dication is closed-shell, the species is spinless, and therefore the generated species cannot have been detected by EPR spectroscopy. The broad and structure-less EPR spectra make it difficult to analyse hyperfine coupling constants (hfcc) and thereby to experimentally identify the structure of the radical species. But, the theoretical calculations provided a reasonable chemical interpretation on the EPR experiments. The spin of radical cation and diradical dication of MC is delocalized over the whole molecule, mainly on the donor units (Figure 6d), which is in good agreement with the observed broad and structure-less EPR spectra. Furthermore, calculations indicated that the triplet configuration of the open-shell radical dication is slightly more stable than open-shell singlet biradical dication (for details, see the SI). After the polarization of the working electrode to the potential of $0.8 \mathrm{~V}\left(\mathrm{vs}\right.$. $\left.\mathrm{Fc} / \mathrm{Fc}^{+}\right)$, which corresponds to the 2 nd oxidation process in $\mathrm{CV}$, an EPR signal 

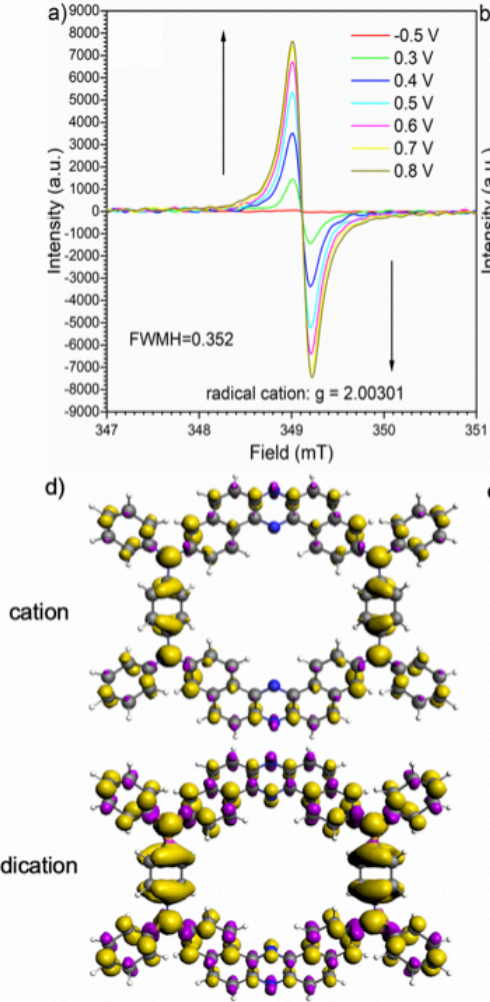

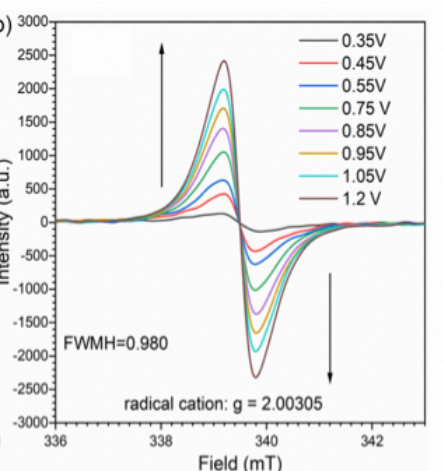

e)

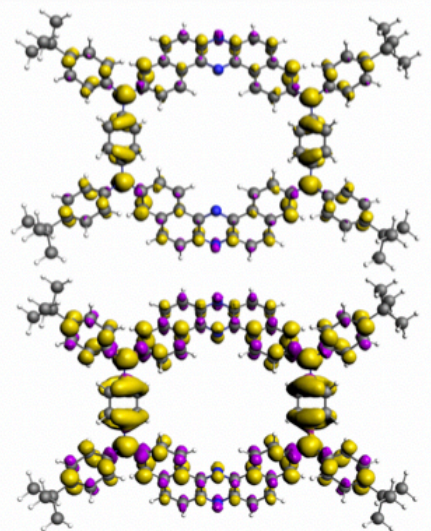

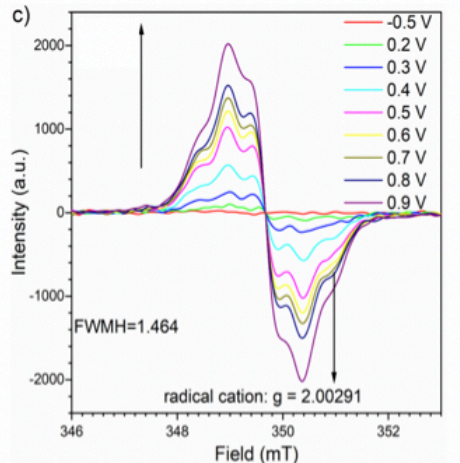

f)
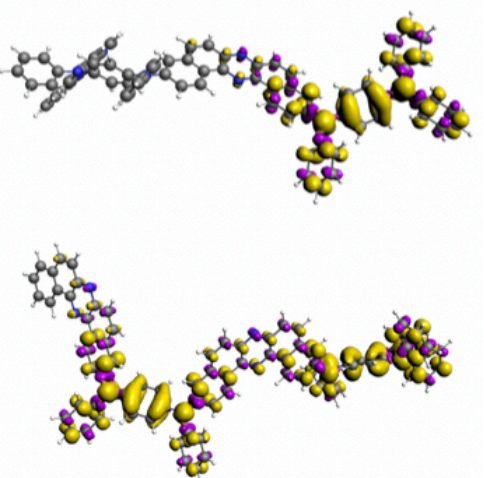

Figure 6. Potentiostatic EPR spectroelectrochemistry of (a) $0.50 \mathrm{mM} \mathrm{MC}$, (b) $0.25 \mathrm{mM}$ tBuMC, and (c) $0.50 \mathrm{mM} \mathrm{Linear} \mathrm{in} \mathrm{DCM} \mathrm{Bu}_{4} \mathrm{NBF}_{4}(0.1 \mathrm{M})$ electrolyte. Spin density map of cation and dication of (d) MC, (e) tBuMC, and (f) Linear (DFT calculations at the PBE0/TZP level).

kept active, and the intensity continuously increased (Figure 6a). In conjunction with results obtained with $\mathrm{CV}$ and spectroelectrochemistry, we can conclude that EPR-active (openshelled) trication and tetracation species are formed in the second oxidation step. Similar behaviour was observed for $\mathbf{t B u M C}$ and Linear (Figure $6 \mathrm{~b}$ and $\mathrm{c}$ ). When we compare MC and $\mathbf{t B u M C}$, the signal of $\mathbf{t B u M C}$ is much broader than MC (Figure $6 a$ and b), probably due to the additional hyperfine couplings contributed by twelve hydrogen nuclei on four $t \mathrm{Bu}$ groups. In the case of Linear, the EPR signal splitting was more distinct than macrocycles, which should be proof that the spins are more localized (Figure $6 c)$. This was supported by the calculation, which clearly shows that the spins are localized on donor units: the spin of the radical cation is located on the terminal donor unit, while the spin of the diradical dication on the terminal and the internal donor (Figure $6 f)$.

\section{Potentiodynamic UV-Vis-NIR spectroelectrochemistry}

To obtain insight into the dynamic aspects of the molecular change under the electrochemical stimuli, the dynamic spectroelectrochemical analysis during the cyclic voltammperometry process was conducted. ${ }^{[33]}$ All the electrochemical and potentiostatic spectroelectrochemical analysis give a clue to the compounds behaviour and the difference between them. Importantly, the potentiodynamic analysis reveals why $t$ BuMC acts poorly in devices and the origin of the low stability of the $t$ BuMC-based devices. The potentiodynamic UV-Vis spectroelectrochemistry of compounds was employed to understand why we have a significant difference in $\mathrm{CV}$ between $\mathbf{M C}$, Linear and $\mathbf{t B u M C}$. The process was conducted with similar conditions for the CV experiment (Figure 2). When compare to the potentiostatic process, in all cases, the absorption bands corresponding to the neutral form does not increase upon oxidation [i.e, $\lambda_{\text {abs }}(\mathbf{M C})=385,480 \mathrm{~nm}$; $\lambda_{\text {abs }}$ $\left(\right.$ tBuMC) $=334,482 \mathrm{~nm}$; and $\lambda_{\text {abs }}$ (Linear) $=332,481 \mathrm{~nm}$ ) (Figure $7 \mathrm{a}, \mathrm{c}$, and e). Nevertheless, the new band between those maxima (ca. $420 \mathrm{~nm}$ ) is formed. This would explain the observation of the increase in the absorption in the potentiostatic process (Figure 5). During the dedoping process, we observed a recursive decrease of spectra in a similar but opposite way to the doping process (Figure $7 \mathrm{~b}, \mathrm{~d}$, and f). To closer look at the behaviour and the dynamic aspects of the process, the particular wavelength was chosen to make voltabsorptiometric curves (Figure $7 \mathrm{~g}, \mathrm{~h}$, and i). ${ }^{[33]}$ After the oxidation of the MC, the decrease in the intensity of neutral bands ( $\lambda=335$ and $480 \mathrm{~nm}$ ) was observed, together with the intensity increase of the IV-CT bands of radial cationic/diradical dicationic species $(\lambda=945 \mathrm{~nm})$ and monoradical tricationic/closed-shell tetracationic species $(\lambda=623 \mathrm{~nm})$ (Figure $7 \mathrm{~g}$ ). Interestingly, after cycling back, we observed a synchronized change of the absorption bands at 335 and $623 \mathrm{~nm}$, and the bands at 480 and $945 \mathrm{~nm}$, where one increases while the other decreases (black vertical lines in Figure $7 \mathrm{~g}$ ). This would suggest that they are connected with the same oxidation stages.

As earlier-mentioned, Linear displays electrochemical responses typical for conjugated aromatic amines. Through the oxidation of Linear, the decrease of the absorption bands of neutral state $(\lambda=332$ and $481 \mathrm{~nm})$ and the sequential increase of IV-CT bands ( $\lambda=910 \mathrm{~nm}$ and $624 \mathrm{~nm}$ ) were observed (Figure $7 \mathrm{i}$ ). After cycling back, the IV-CT band decreased, and the neutral bands reverted (Figure 7i). A significant difference was observed for $\boldsymbol{t B u M C}$ : The beginning of the oxidation looks more or less similar to the others. The decrease of the neutral band $(\lambda=334$ 


\section{FULL PAPER}
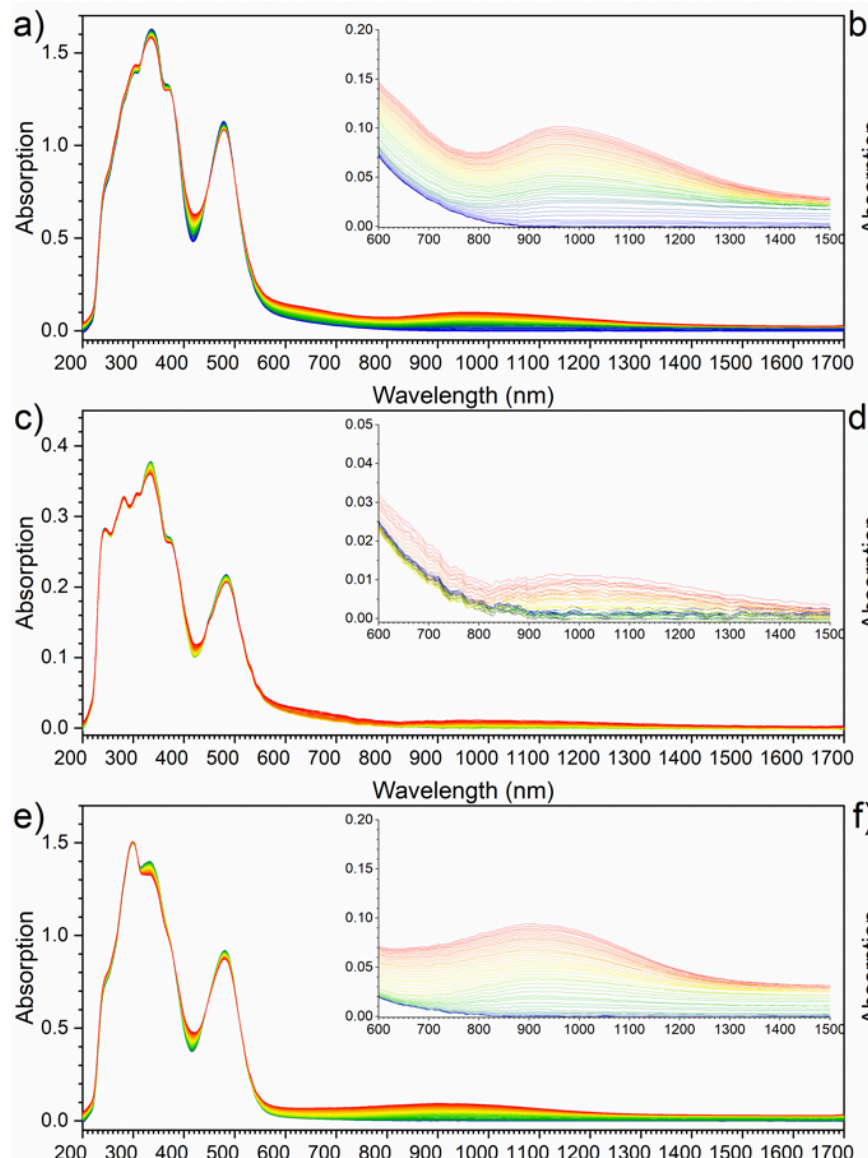

Wavelength $(\mathrm{nm})$
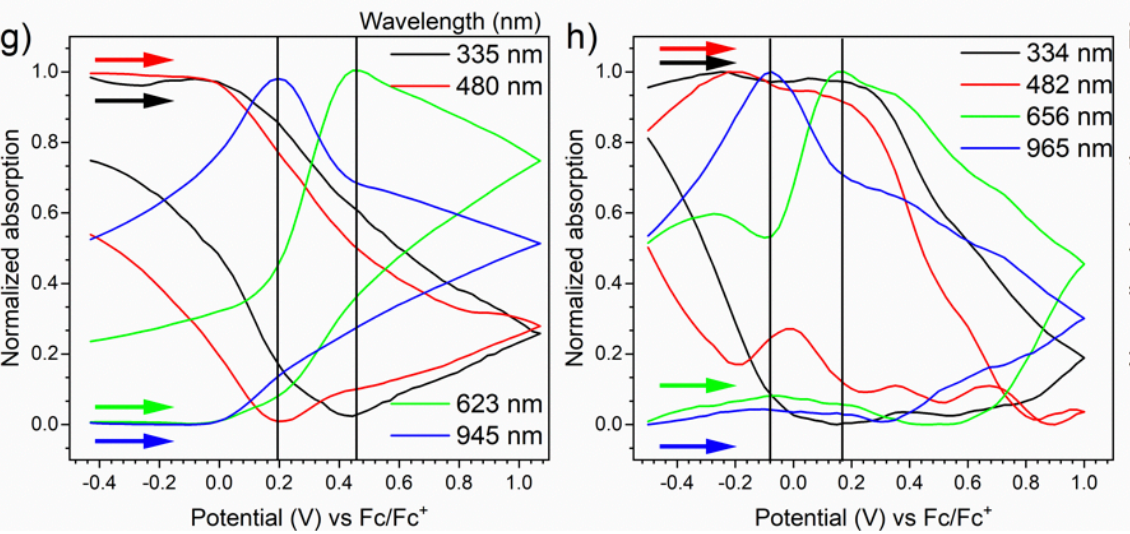
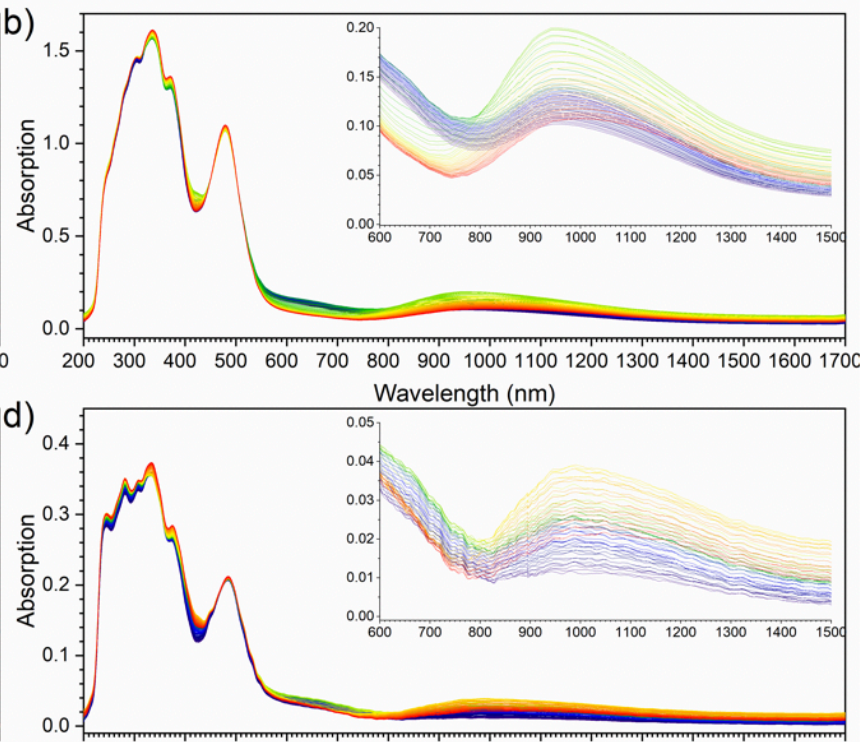

20030040050060070080090010001100120013001400150016001700 Wavelength $(\mathrm{nm})$

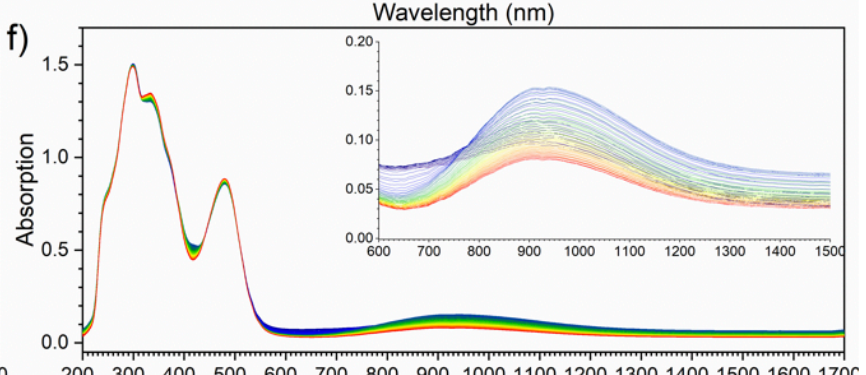
Wavelength (nm)

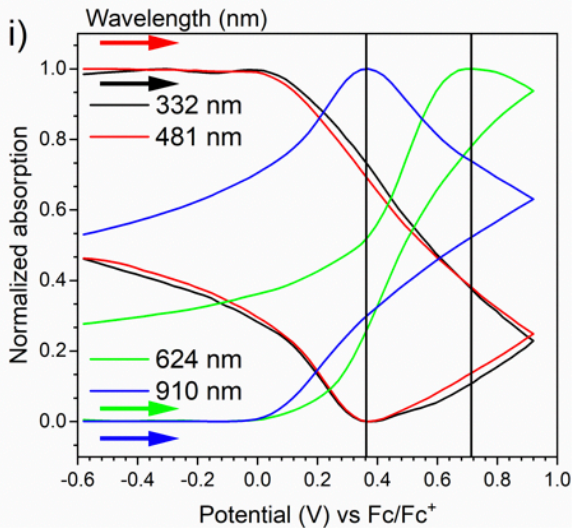

Figure 7. Potentiodynamic UV-Vis-NIR spectroelectrochemistry of doping process of (a) $0.50 \mathrm{mM} M C$, (c) $0.25 \mathrm{mM} t \mathrm{BuMC}$, and (e) $0.50 \mathrm{mM}$ Linear; dedoping process of (b) $0.50 \mathrm{mM} \mathrm{MC,} \mathrm{(d)} 0.25 \mathrm{mM} t \mathrm{tBuMC}$, and (f) $0.50 \mathrm{mM}$ Linear in $\mathrm{DCM} \mathrm{Bu}_{4} \mathrm{NBF}_{4}(0.1 \mathrm{M})$ electrolyte, scan rate $50 \mathrm{mV} / \mathrm{s}$. Cyclicvoltabsorptiometric measurement of (g) $0.50 \mathrm{mM} \mathrm{MC}$, (h) $0.25 \mathrm{mM}$ tBuMC, and (i) $0.50 \mathrm{mM}$ Linear in $\mathrm{DCM} \mathrm{Bu}_{4} \mathrm{NBF}_{4}(0.1 \mathrm{M})$ electrolyte, scan rate $50 \mathrm{mV} / \mathrm{s}$.

and $482 \mathrm{~nm})$ and the increase of IV-CT band $(\lambda=965 \mathrm{~nm})$ were observed as the potential increases, but the IV-CT band $(\lambda=965$ $\mathrm{nm}$ ) started to form way before the intensity of the neutral bands rapidly drop (Figure $7 \mathrm{~h}$ ). This incoherent behavior would suggest the problems of the doping of the diradical dication of $t$ BuMC. Nevertheless, the process is more chaotic on de-doping (Fig. 7d). This seems to be connected with the second oxidation process, and the reduction of monoradical trication/closed-shell tetracation species to diradical dication/radical cation species could be disturbed. Such a difference between $\mathbf{M C}$ and $\mathbf{t B u M C}$ would be mostly caused by structural changes. As in common with conjugated molecules, during the oxidation, quinoidal structures should be formed to allow the electron transfer, which often accompanies with the planarization of the molecule. ${ }^{[34]}$ In the case of MC, we observed certain symmetry which allows for the generation of monoradical trication/closed-shell tetracation directly after the diradical dicationic state. This was observed by the appearance of the band around $600-750 \mathrm{~nm}$, before it was possible to distinguish from monoradical cationic/diradical dicationic species (Figure 5a). Opposite behavior was observed for $\boldsymbol{t B u M C}$. After the first oxidation, the structure is probably locked as we have additional steric hindrance group, which is causing problems with doping and flattening of the structure. ${ }^{[35]}$ This would suggest that the structure of $\mathbf{t B u M C}^{2+}$ is not symmetrical, and the charges are not uniformly distributed. Moreover, what was observed in electrochemical and spectroelectrochemical behavior of $t$ BuMC is there is an evident problem with the de-doping process, which was caused by the second quasi-reversible oxidation process in the CV. Such asymmetric structural changes would be caused in the emissive 
layer after charge-injection, which would cause a partial degradation of $\boldsymbol{t} \mathrm{BuMC}^{2+}$ and thereby lowering the efficiency and roll-off of the device.

\section{Conclusion}

A new purely-organic macrocyclic TADF compound (tBuMC) was synthesized, and its detailed electrochemical and photophysical properties were characterized by various methods. The OLED devices fabricated with the developed macrocyclic D-A-D-A compound (tBuMC) achieved rather high EQEs greater than $10 \%$, which is much higher than those fabricated with Linear $(6.9 \%)$ and a 1 st generation fluorescent emitter (5\%). On one hand, the OLED exhibits a slightly lower EQE and greater efficiency roll-off than those of the OLED fabricated with previously reported macrocyclic TADF emitter (MC). The comparative electrochemical studies of $\mathbf{t B u M C}, \mathbf{M C}$, and Linear revealed that the introduction of $t$-Bu groups on the exterior $\mathrm{N}$-aromatic rings causes a slightly negative shift in the oxidation potentials and the electrochemical irreversibility in the 2nd oxidation step. Spectroelectrochemistry and EPR analyses, taken together with theoretical calculations, suggested the both of the 1st and 2nd oxidation of the macrocycles in $\mathrm{CV}$ involve two-electron transfer to generate open-shell diradical dications and closed-shell tetracations, respectively. Furthermore, the potentiodynamic analysis reveals why $t B u M C$ acts poorly in devices and the origin of the low stability of the $t$ BuMC-based devices. Such combinational spectrochemical and theoretical analyses of organic molecules present as a powerful tool to explain why certain molecules even with very good emissive properties are not as good as OLED emitters. Analysis of an OLED gives only global behavior of the device, and it is difficult to analyse particular layers. In this case, by employing broad electrochemical and spectroelectrochemical study, we were able to understand the influence of the molecular structure on the molecular charge stability and involved side processes which would not be possible to do it in OLED device.

\section{Acknowledgements}

P.D. and A.N. acknowledge the support received from the First Team program of the Foundation for Polish Science co-financed by the European Union under the European Regional Development Fund (project number: POIR.04.04.00-00-4668/1700). P.deS. acknowledges support by a research grant (00028053) from VILLUM FONDEN. S.P. acknowledges the support received from Polish National Science Centre, project No. 2019/35/D/ST5/01136. Y.T., S.P., and P.D. acknowledge the EU's Horizon 2020 for funding the OCTA project under grant agreement No. 778158. Y.T. acknowledges a Grant-in-Aid for Scientific Research on Innovative Areas " $\pi$-System Figuration: Control of Electron and Structural Dynamism for Innovative Functions" (JSPS KAKENHI Grant Number JP15H00997 \& JP17H05155) and "Aquatic Functional Materials: Creation of New Materials Science for Environment-Friendly and Active Functions" (JSPS KAKENHI Grant Number JP19H05716) from the MEXT (Ministry of Education, Culture, Science and Technology, Japan), and the Research Grant from the Japan Prize Foundation, and the Continuation Grants for Young Researchers from the Asahi Glass Foundation, and the Research Grant in the Natural Science from the Mitsubishi Foundation. We acknowledge Prof. Taro Uematsu at Osaka University for fruitful discussions on electrochemical analysis.

Keywords: electrochemistry $\cdot$ macrocycles $\cdot$ organic lightemitting diodes $\cdot$ redox $\bullet$ thermally activated delayed fluorescence

[1] a) M. A. Baldo, D. F. O'Brien, Y. You, A. Shoustikov, S. Sibley, M. E. Thompson, S. R. Forrest, Nature 1998, 395, 151-154; b) C. Adachi, M. A. Baldo, M. E. Thompson, S. R. Forrest, J. Appl. Phys. 2001, 90, 50485051 .

[2] M. A. Baldo, S. Lamansky, P. E. Burrows, M. E. Thompson, S. R. Forrest, Appl. Phys. Lett. 1999, 4, 4-7.

[3] G. J. Hedley, A. Ruseckas, I. D. W. Samuel, Chem. Phys. Lett. 2008 450, 292-296.

[4] T. Tsuboi, M. Tanigawa, Thin Solid Films 2003, 439, 301-307.

[5] T. Hofbeck, H. Yersin, Inorg. Chem. 2010, 49, 9290-9299.

[6] D. Volz, M. Wallesch, C. Fléchon, M. Danz, A. Verma, J. M. Navarro, D. M. Zink, S. Bräse, T. Baumann, Green Chem. 2015, 17, 1988-2011.

[7] Y. Tao, K. Yuan, P. Xu, H. Li, R. Chen, C. Zheng, L. Zhang, W. Huang, Adv. Mater. 2014, 26, 7931-7958.

[8] "New Generation of High Efficient OLED Using Thermally Thermally Activated Activated Delayed Delayed Fluorescent Fluorescent Materials Materials Manish": M. Kumar, M. Ribeiro, L. Pereira in Light-Emitting Diode: An Outlook On the Empirical Featurres and Its Recent Technological Advancements (Ed.: J. Thirumalai), 2018, London, IntechOpen, pp. 103-126.

[9] M. K. Etherington, J. Gibson, H. F. Higginbotham, T. J. Penfold, A. P. Monkman, Nat. Commun. 2016, 7, 1-7

[10] T.-T. Bui, F. Goubard, M. Ibrahim-Ouali, D. Gigmes, F. Dumur, Beilstein J. Org. Chem. 2018, 14, 282-308.

[11] Y. Im, M. Kim, Y. J. Cho, J.-A. Seo, K. S. Yook, J. Y. Lee, Chem. Mater. 2017, 29, 1946-1963.

[12] B. Yurash, H. Nakanotani, Y. Olivier, D. Beljonne, C. Adachi, T.-Q. Nguyen, Adv. Mater. 2019, 31, 1804490/1-8.

[13] P. de Silva, J. Phys. Chem. Lett. 2019, 10, 5674-5679.

[14] P. de Silva, C. A. Kim, T. Zhu, T. Van Voorhis, Chem. Mater. 2019, 31, 6995-7006.

[15] A. P. Kulkarni, X. Kong, S. A. Jenekhe, Adv. Funct. Mater. 2006, 16, 1057-1066.

[16] Y. Olivier, M. Moral, L. Muccioli, J.-C. Sancho-García, J. Mater. Chem. C 2017, 5, 5718-5729.

[17] T. Serevičius, R. Skaisgiris, J. Dodonova, L. Jagintavičius, J. Bucevičius, K. Kazlauskas, S. Juršènasa, S. Tumkevičius, Chem. Commun. 2019, 55, 1975-1978.

[18] a) K. Wang, C.-J. Zheng, W. Liu, K. Liang, Y.-Z. Shi, S.-L. Tao, C.-S. Lee, X.-M. Ou, X.-H. Zhang, Adv. Mater. 2017, 29, 1701476/1-9; b) F.-M. Xie, J.-X. Zhou, Y.-Q. Li, J.-X. Tang, J. Mater. Chem. C 2020, 8, 9476-9494.

[19] a) P. Data, Y. Takeda, Chem. Asian J. 2019, 14, 1613-1636; b) Y. Takeda, P. Data, S. Minakata, Chem. Commun. 2020, 36, 8884-8894.

[20] A. Endo, M. Ogasawara, A. Takahashi, D. Yokoyama, Y. Kato, C. Adachi, Adv. Mater. 2009, 21, 4802-4806.

[21] N. Uchida, T. Sato, J. Kuwabara, Y. Nishimura, T. Kanbara, Chem. Lett. 2014, 43, 459-461. 
[22] S. Izumi, H. F. Higginbotham, A. Nyga, P. Stachelek, N. Tohnai, P. de Silva, P. Data, Y. Takeda, S. Minakata, J. Am. Chem. Soc. 2020, 142, 1482-1491.

[23] C. Wu, P. I. Djurovich, M. E. Thompson, Adv. Funct. Mater. 2009, 19, 3157-3164.

[24] Y. Takeda, M. Okazaki, S. Minakata, Chem. Commun. 2014, 50, 10291 10294.

[25] C. M. Cardona, W. Li, A. E. Kaifer, D. Stockdale, G. C. Bazan, Adv. Mater. 2011, 23, 2367-2371.

[26] J.-L. Bredas, Mater. Horiz. 2014, 1, 17-19.

[27] M. A. El-Sayde, Acc. Chem. Res. 1968, 1, 8-16.

[28] C. Lambert, G. Nöll, J. Am. Chem. Soc. 1999, 121, 8434-8442.

[29] V. Coropceanu, M. Malagoli, J. M. André, J. L. Brédas, J. Am. Chem. Soc. 2002, 124, 10519-10530.

[30] A. V. Szeghalmi, M. Erdmann, V. Engel, M. Schmitt, S. Amthor, V. Kriegisch, G. Nöll, R. Stahl, C. Lambert, D. Leusser, D. Stalke, M. Zabel, J. Popp, J. Am. Chem. Soc. 2004, 126, 7834-7845.

[31] A. Ito, J. Mater. Chem. C 2016, 4, 4614-4625.

[32] T.-F. Yang, K. Y. Chiu, H.-C. Cheng, Y. W. Lee, M. Y. Kuo, Y. O. Su, J. Org. Chem. 2012, 77, 8627-8633.

[33] a) P. Data, R. Motyka, M. Lapkowski, J. Suwinski, A. Monkman, J. Phys. Chem. C 2015, 119, 20188-20200; b) P. Data, P. Pander, P. Zassowski, V. Mimaite, K. Karon, M. Lapkowski, J. Grazulevicious, P. Slepski, K. Darowicki, Electrochim. Acta 2017, 230, 10-21; c) S. Pluczyk, M. Vasylieva, P. Data, J. Vis. Experim. 2018, 140, e56656.

[34] a) Z. Zeng, X. Shi, C. Chi, J. T. L. Navarrete, J. Casado, J. Wu, Chem. Soc. Rev. 2015, 44, 6578-6596; b) P. Kar, Doping in Conjugated Polymers, John Wiley and Sons, Inc., 2013; c) Handbook of Advanced Electronic and Photonic Materials and Devices (Ed.: H. S. Nalwa), 2001, Academic Press, London; d) S. L. Pittelli, M. De Keersmaecker, J. F. Ponder Jr, A. M. Österholm, M. A. Ochieng, J. R. Reynolds, J. Mater. Chem. C 2020, 8, 683-693.

[35] a) L. Colella, L. Brambilla, V. Nardone, E. Parisini, C. Castiglionia, C. Bertarelli, Phys. Chem. Chem. Phys. 2015, 17, 10426-10437; b) J. Casado, R. P. Ortiz, J. T. L. Navarrete, Chem. Soc. Rev. 2012, 41, 56725686; c) S. Wang, D. Fazzi, Y. Puttisong, M. J. Jafari, Z. Chen, T. Ederth, J. W. Andreasen, W. M. Chen, A. Facchetti, S. Fabiano, Chem. Mater. 2019, 31, 3395-3406; d) Handbook of UV Degradation and Stabilization (Ed.: G. Wypych), 2015, ChemTec Publishing, Toronto. 
WILEY-VCH

\section{FULL PAPER}

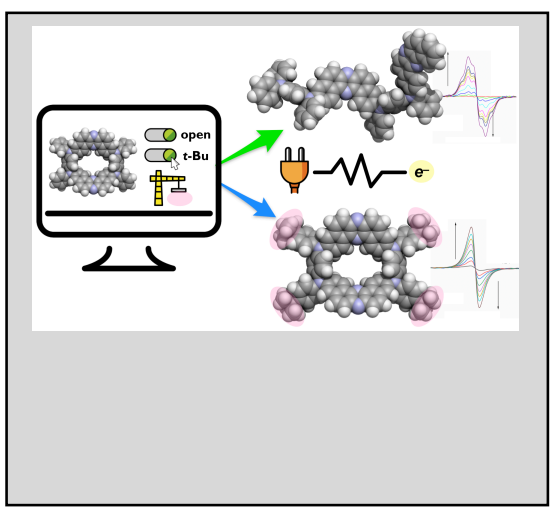

A new derivative of purely-organic thermally activated delayed fluorescent macrocyclic compound has been synthesized.

Comparative studies on the electrochemical and photophysical properties of the compound and its parent compound and a linear analogue have been investigated. Slight structural modification of the macrocycle caused a significant difference in the EQE roll-off of the OLED devices. Further experiments and theoretical calculations revealed the effect of the structural modification on the properties and EQE roll-off.

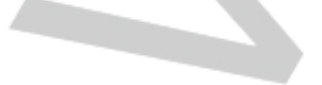

Institute and/or researcher Twitter usernames: @Piotr_deSilva, @MinakataLab, @Takephos, @osaka-univ_e 